Corbato, Román.

Investigador predoctoral, Universidad de Vigo, Departamento de Pintura, Grupo de Investigación DX7.

\title{
Del mapa al drone: paisajes contemporáneos, nuevas interpretaciones del territorio.
}

\author{
TIPO DE TRABAJO
}

Comunicación.

PALABRAS CLAVE

Paisaje, territorio, mapa, digital.

KEY WORDS

Landscape, territory, map, digital.

\section{RESUMEN}

Desde hace unos 4000 años se vienen realizando imágenes gráficas que representan territorios concretos a las que llamamos mapas. Estas representaciones geográficas han sido decisivas para la aparición de la idea de paisaje.

A partir de la segunda mitad del siglo XVI, son los pintores los que orientan su mirada hacia el territorio gracias a la creación de estas imágenes o mapas por parte de los geógrafos y cartógrafos. Durante las vanguardias, ni los dadaístas ni los surrealistas llegan a trasladar sus acciones a unas bases cartográficas y, además, huyen de las representaciones mediante las descripciones literarias. Por su parte, los situacionistas realizan mapas psicogeográficos, pero sin la intención de representar las trayectorias reales de sus derivas. No es hasta la década de los años 60, cuando algunos artistas como Smithson, Long o Fulton, deciden confrontar el mundo del arte con el problema de la representación y conocimiento del territorio, por lo que recurren al uso de mapas como instrumentos expresivos. En la actualidad, las nuevas tecnologías permiten viajar por todo el mundo desde un ordenador conectado a Internet: se pueden explorar los lugares que se quiera, dar un paseo virtual o incluso señalar un lugar como visitado. Los métodos cartográficos contemporáneos incluyen satélites, superordenadores, aparatos voladores no tripulados o cámaras capaces de captar imágenes de 360 grados.

El objeto de este artículo es, por un lado, analizar la evolución de las distintas actitudes artísticas frente a la representación del territorio mediante el uso de mapas y otros dispositivos cartográficos digitales. Y, por otro, desvelar cómo los métodos de conocimiento virtuales del territorio han transformado la manera en que al artista contemporáneo mira y se enfrenta al paisaje. Así, modificado el punto de vista, el paisaje pierde su inercia y la creación artística se abre hacia formas completamente nuevas de concebir sus relaciones con el medio natural.

\section{ABSTRACT}

For approximately 4000 years they come realizing graphical images that represent concrete territories those that we are called maps. These geographical representations have been decisive for the appearance of the idea of landscape.

From the second half of the 16th century, they are the painters those who orientate his look towards the territory thanks to the creation of these images or maps on the part of the geographers and cartographers. Neither during the forefronts, nor the dadaístas nor surrealistic his actions manage to move to a few cartographic bases and, in addition, they flee of the representations by means of the literary descriptions. For your part, the situacionistas realize maps psicogeográficos, but without the intention of representing the royal paths of his drifts. It is not up to the decade of the years

From the second half of the 16th century, they are the painters those who orientate his look towards the territory thanks to the creation of these images or maps on the part of the geographers and cartographers. Neither during the forefronts, nor the dadaístas nor surrealistic his actions manage to move to a few cartographic bases and, in addition, they flee of the representations by means of the literary descriptions. For your part, the situacionistas realize maps psicogeográficos, but without the intention of representing the royal paths of his drifts. It is not up to the decade of the 60s, when some artists like 
Smithson, Long or Fulton, they decide to confront the world of the art with the problem of the representation and knowledge of the territory, for what they resort to the use of maps as expressive instruments. At present, the new technologies allow to travel all over the world from a computer connected to Internet: there can be explored the places that are wanted, give a virtual or enclosed walk to indicate a place as visited. The cartographic contemporary methods include satellites, supercomputers, flying not crewed devices or chambers capable of catching images of 360 degrees.

The object of this article is, on the one hand, to analyze the evolution of the different artistic attitudes opposite to the representation of the territory by means of the use of maps and other cartographic digital devices. And, for other one, to reveal how the virtual methods of knowledge of the territory have transformed the way that looks at the contemporary artist and faces the landscape. This way, modified the point of view, the landscape loses his inertia and the artistic creation is opened towards completely new ways of conceiving his relations with the natural way.

\section{CONTENIDO}

\section{INTRODUCCIÓN}

Desde hace unos 4000 años se vienen realizando imágenes gráficas que representan territorios concretos a las que llamamos mapas. Estas representaciones geográficas han sido decisivas para la aparición de la idea de paisaje.

A partir de la segunda mitad del siglo XVI, son los pintores los que orientan su mirada hacia el territorio gracias a la creación de estas imágenes o mapas por parte de los geógrafos y cartógrafos. Durante las vanguardias, ni los dadaístas ni los surrealistas llegan a trasladar sus acciones a unas bases cartográficas y, además, huyen de las representaciones mediante las descripciones literarias. Por su parte, los situacionistas realizan mapas psicogeográficos, pero sin la intención de representar las trayectorias reales de sus derivas. No es hasta la década de los años 60, cuando algunos artistas como Robert Smithson, Richard Long o Hamish Fulton, deciden confrontar el mundo del arte con el problema de la representación y conocimiento del territorio, por lo que recurren al uso de mapas como instrumentos expresivos. En la actualidad, las nuevas tecnologías permiten viajar por todo el mundo desde un ordenador conectado a Internet: se pueden explorar los lugares que se quiera, dar un paseo virtual o incluso señalar un lugar como visitado. Los métodos cartográficos contemporáneos incluyen satélites, superordenadores, aparatos voladores no tripulados o cámaras capaces de captar imágenes de 360 grados.

El objeto de este artículo es, por un lado, analizar distintas actitudes artísticas frente a la representación del territorio mediante el uso de mapas y otros dispositivos cartográficos digitales. Y, por otro, desvelar cómo los métodos de conocimiento virtuales del territorio han transformado la manera en que al artista contemporáneo mira y se enfrenta al paisaje. Así, modificado el punto de vista, el paisaje pierde su inercia y la creación artística se abre hacia formas completamente nuevas de concebir sus relaciones con el medio natural.

\section{1.- NUEVAS APROXIMACIONES A LOS CONCEPTOS DE PAISAJE, TERRITORIO, MAPA Y GEOGRAFÍA}

Las palabras "paisaje" y "territorio" están cargadas de significados y acepciones que se entrelazan y enmarañan con los mapas y la geografía, razón por la cual es necesario situarlos hoy en el contexto de una sociedad, una cultura y una situación económica concretas.

Javier Maderuelo considera que de la constatación de las diferencias entre los distintos territorios que se perciben cuando se viaja de un país a otro procede el término paisaje. Por lo tanto, "la idea de paisaje se empieza a perfilar cuando se contempla el territorio" ${ }^{1}$. De este modo, podemos considerar que el paisaje es "la interpretación de lo que se ve en el país (territorio) cuando esté se contempla con mirada estética" ${ }^{2}$. Por su parte, Alain Roger, en su Breve tratado del paisaje, señala que "el país es, en cierto modo, el grado cero del paisaje ${ }^{\prime 3}$. En este sentido, no hay paisaje sin país, sin territorio.

El paisaje es así el efecto de la superposición de la actividad humana sobre la naturaleza, e incluye las modificaciones derivadas de la actuación sobre el medio para hacerlo productivo y construir artificialmente sobre él, ya sean infraestructuras (puentes, presas, caminos, etc.) o realizaciones propiamente arquitectónicas. En efecto, el espacio geográfico es el soporte concreto del paisaje. Según Vidal de La Blache: "la naturaleza prepara el sitio, y el hombre lo organiza de tal manera que satisfaga sus necesidades y deseos" ${ }^{4}$. Se

1 ANSÓN, Antonio, et al. Paisaje y territorio. MADERUELO, Javier (dir.). Madrid: Abada Editores, 2008, p. 6.

2 Ibídem.

3 ROGER, Alain. Breve tratado del paisaje. MADERUELO, Javier (ed.). Madrid: Biblioteca Nueva, 2007, p. 23.

4 CHUECA, Fernando. Breve historia del urbanismo. Madrid: Alianza Editorial, 2000, p. 7. 
trata, por tanto, de un término que implica una orientación proyectual clara y una condición híbrida, natural y artificial: "la proyección de la cultura sobre el territorio natural" ${ }^{5}$.

Sobre el término "territorio" debiera anotarse su diferencia esencial frente al término "paisaje": mientras este último implica un punto de vista a la altura de la visión humana y una orientación "plástica", "territorio" siempre designa el mismo objeto desde el punto de vista denominado "a vista de pájaro", de forma abstracta o con una voluntad "cientifista", describiendo bien los campos de acción y, por lo mismo, muchas de las oposiciones culturales entre algunas disciplinas, como pueden ser el paisajismo o el urbanismo.

La escala y el territorio, dos de los temas que estamos tratando aquí, se encuentran relacionados en un documento gráfico muy particular: el mapa. "El mapa representa el conocimiento intelectual, la convención lingüística, mientras que el territorio se refiere a la experiencia física, al hecho sensorial. La comparación entre mapa y territorio resulta fascinante, porque se trata de relacionar conocimiento con experiencia" ${ }^{6}$. Hablar de mapas, es hablar de la mirada científica que cuando se encuentra con la mirada artística, que configura el paisaje, generan estructuras de pensamiento y comprensión del territorio.

El Diccionario de la Real Academia de la Lengua Española define geografía como la "ciencia que trata de la descripción de la Tierra". Si tenemos en cuenta la idea de que el conocimiento, no sólo científico, responde a la voluntad de medir el "todo", comprenderemos rápidamente que cada vez más la geografía tiene que ver, ya no sólo con describir el mundo que nos rodea, sino con medirlo y analizar los cambios de escala que se están produciendo. Sabemos que toda descripción del mundo implica la noción de representación, peo debemos preguntarnos si "representar la realidad" forma todavía parte de la misión de los artistas.

“[...] La geografía de los artistas contemporáneos explora a partir de ahora los modos de habitar, las múltiples redes en las que evolucionamos, los circuitos por los que nos desplazamos y, sobre todo, las formaciones económicas, sociales y políticas que delimitan los territorios humanos. Aquí están algunos de los temas mayores del arte actual, atravesado por la obsesión de describir el planeta y de utilizar sus espacios, con la ayuda de investigaciones, puesta en escena y discursos" ${ }^{7}$.

\section{2.- CAMINAR EL MAPA}

“Caminar implica una relación directa con las cosas generándose una confrontación y diálogo con la noción de paisaje como elemento cultural que cuestiona el territorio y dialoga con él" ${ }^{8}$.

Uno de los principales problemas del arte de andar es la traducción de dicha experiencia a una forma estética. Ni los dadaístas ni los surrealistas trasladaron sus acciones a unas bases cartográficas $y$, además, huyeron de las representaciones mediante las descripciones literarias. Los situacionistas realizaron mapas psicogeográficos, pero nunca quisieron representar las trayectorias reales de sus derivas. Por el contrario, deseando confrontarse con el mundo del arte y por tanto con el problema de la representación, artistas como Richard Long o Hamish Fulton recurren al uso de mapas como instrumentos expresivos.

Para Long el andar es una acción que interviene en el lugar. "Es un acto que dibuja una figura sobre el terreno y que, por tanto, puede trasladarse a una representación cartográfica. Pero el procedimiento puede ser utilizado de modo inverso: el plano puede funcionar como un soporte sobre el cual se dibujan unas figuras que se recorrerán posteriormente" ${ }^{9}$. (llustración 1)

Richard Long considera que un mapa puede ser usado para dar un paseo o para hacer una obra de arte. Los mapas tienen capas de información que enseñan la historia, la geografía o la toponimia de los lugares. Son una combinación artística y poética de imagen y lenguaje, por lo que son una potente alternativa a las fotografías, ya que tienen funciones diferentes: pueden mostrar la idea completa de un proyecto (tiempo y espacio), no sólo un momento. La distancia recorrida, los días caminados, los lugares de acampada o la forma de la caminata pueden ser representados de una forma concisa en una sola imagen. En algunas de sus obras, encuentra los lugares analizando primero el mapa, ya que con él se pueden decidir el lugar y/o la idea. Los mapas tienen un lenguaje universal y se pueden leer de muchas maneras ${ }^{10}$.

5 ÁBALOS, Iñaki. Atlas pintoresco. Vol. 1: el observatorio. Barcelona: Gustavo Gili, 2005, p. 42.

6 MADERUELO, Javier. El espacio raptado. Interferencias entre Arquitectura y Escultura. Madrid: Mondadori, 1990, p.196.

7 BOURRIAUD, Nicolas. "Topocrítica. El arte contemporáneo y la investigación geográfica". En: HERNÁNDEZ-NAVARRO, Miguel Ángel (coord.). Heterocronías. Tiempo, arte y arqueologías del presente. Murcia: Cendeac, 2008, p. 17-18.

8 MEANA, Juan Carlos. "Paisajeando: orden de la experiencia vs. desorden del paisaje en la obra de Christian García Bello y Román Corbato". :Estudio, Artistas sobre outras Obras. 2015, vol 6, núm. 11, enero-junio, p. 235-236.

9 CARERI, Francesco, Walkscapes. El andar como práctica estética. Barcelona: Gustavo Gili, 2005, p. 156.

10 Cfr. LONG, Richard. Richard Long Walking the line. Nueva York: Thames \& Hudson, 2002, p. 84. 


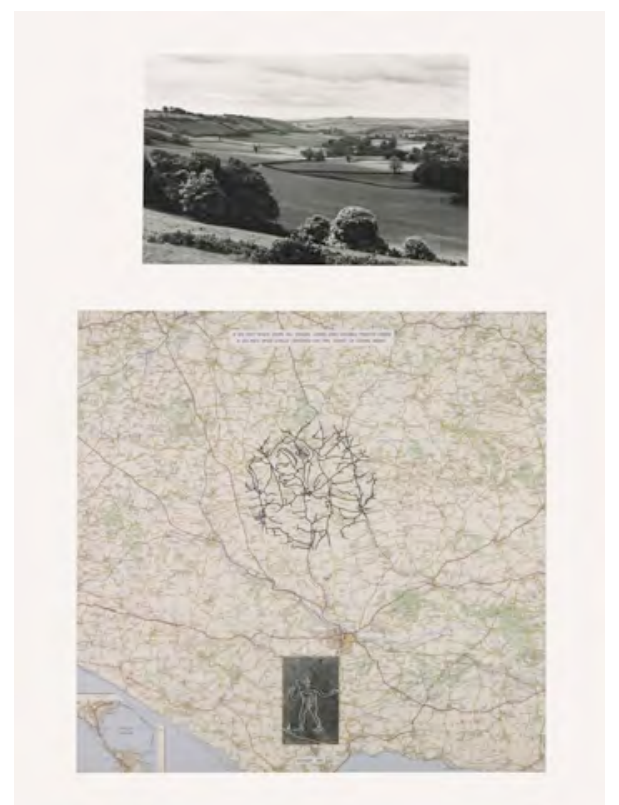

Ilustración 1. Richard Long, A six-Day Walk Over All Roads, Lanes and Double Tracks Inside a Six-Mile-Wide Circle Centered on The Giant of Cerne Abbas, 1975.

Por el contrario, en la obra de Fulton, la representación de los lugares atravesados configura un mapa en un sentido abstracto. La representación del recorrido se resuelve por medio de unas imágenes y unos textos gráficos que dan testimonio de la experiencia de andar, con una conciencia clara de que nunca será posible captarla por completo a través de la representación. A pesar de esto, Fulton utiliza el mapa como registro de esas caminatas, su arte es un gesto simbólico de respeto por la naturaleza viviendo la experiencia de caminar "en el paisaje".

No es de extrañar que una parte importante de la obra de estos dos artistas del Land art aparezca en las galerías de arte en forma de mapas donde se proyecta o se da testimonio de esas acciones "invisibles" y efímeras que han sido o pretenden ser realizadas en el territorio real. La cartografía del Land art se hace caminando, y el plano se vuelve soporte de un itinerario. "El mapa, en estas obras, no sólo es un representación del terreno, sino un acta que da fe de que la obra de arte se ha realizado, de que los presupuestos se han cumplido" ${ }^{11}$.

\section{3.- EVOLUCIÓN DE LA MIRADA SOBRE EL TERRITORIO: DE LA DOBLE ARTEALIZACIÓN A GOOGLE EARTH}

Basándonos en la teoría de la doble artealización de Alain Roger que propone: "La naturaleza es indeterminada y sólo el arte la determina: un país no se convierte en paisaje más que bajo la condición de un paisaje, y esto, de acuerdo con las dos modalidades, móvil (in visu) y adherente (in situ), de la artealización" ${ }^{12}$, podemos relacionar el paisaje y lo pintoresco con la experiencia y mirada directa sobre éste o según la metodología de Alain Roger: artealización in situ. Por otro lado, podríamos asociar la artealización in visu, esto es "crear modelos autónomos que requieren de un intermediario, de una mirada que debe impregnarse de estos modelos culturales para artealizar a distancia" ${ }^{13}$, con los conceptos de territorio y sublime.

Para defender esta hipótesis, analizaremos dos parejas de obras que responden a distintas miradas del territorio por parte de los artistas, desde el punto de vista de lo pintoresco y de lo sublime, y cómo los nuevos sistemas virtuales de representación del territorio han hecho evolucionar el concepto de paisaje.

\section{1.- EVOLUCIÓN DE LO PINTORESCO: ROBERT SMITHSON VS. BASURAMA}

En diciembre de 1967, aparece en la revista Artforum un artículo de Robert Smithson titulado "The Monuments of Passaic", y en ese mismo momento se inaugura en la galería de Virginia Dwan, en Nueva York, una exposción suya. En ella se exhibe un mapa en negativo, además de 24 fotografías en blanco y negro que representan los monumentos de Passaic. Sin embargo no se trata de una exposición de fotografías, sino que, en realidad, los monumentos son extraños objetos tomados de un paisaje industrial de la periferia.

11 MADERUELO, Javier. Opus cit., p. 197.

12 ROGER, Alain. Opus cit., p. 23.

13 Ibídem, p. 22. 
De este modo, Smithson descubre así una nueva posición pintoresca, que surge del mundo heredado de la modernidad industrial como susceptible de ser considerado bello.

Lo pintoresco aquí tiene que ver con lo parcial, con una construcción de la mirada muy original, enfocada hacia el suelo, apenas dejando espacio para el horizonte. "Smithson mira hacia el suelo y se deja arrastrar por la fascinación que le provoca encontrar una nueva forma de accidente y negligencia dotada de unas cualidades matéricas que, intuye, no han sido explotadas plásticamente" ${ }^{14}$. Nos encontramos con esa mirada in situ del artista, de ese viaje pintoresco, únicamente contado mediante un mapa y unas fotografías de modo que se cree un conflicto entre conocimiento y percepción en la mente del espectador. (Ilustración 2)

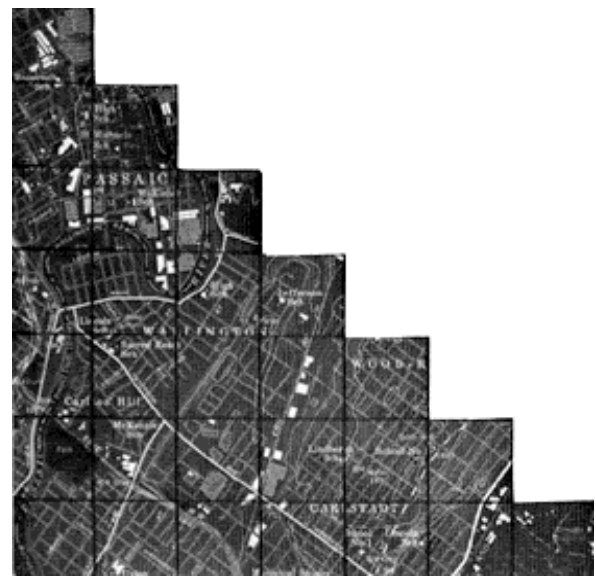

llustración 2. Robert Smithson, Negative Map Showing Region of Monuments along the Passaic River, 1967.

En 2014, el colectivo artístico Basurama participó en la exposición 7.000.000.000 en el Espai d'art contemporani de Castelló para desarrollar una nueva fase del proyecto $6000 \mathrm{~km}$, Defiende el territorio desde el aire, en Castellón. Es un proyecto para reflexionar sobre el metabolismo de las ciudades, que hace visibles paisajes-territorios relacionados con la producción, consumo y desecho de materiales y energía. Se ha docuemntado el territorio mediante fotografías aéreas de bajo coste con globos y/o cometas usando herramientas de Public Laboratory, una asociación y red abierta de ciencia ciudadana. (Ilustración 3)

Con estas nuevas herramientas de fotografía aérea "low cost" este colectivo ha conseguido generar un nuevo tipo de mirada pintoresca en la línea de Robert Smithson. Pero mientras Smithson buscaba una mirada estética en ese viaje pintoresco por la ruinas de Passaic, las imágenes de Basurama denuncian las construcciones industriales de la costa de Castellón. Hay un cambio radical de mirada, ya no se trata de esa búsqueda de lo pintoresco en lo industrial, sino que se trata de una mirada de denuncia, de conciencia ecológica y social. Los dos proyectos coincide en una experimentación del territorio in situ, necesaria para el conocimiento de ese espacio geográfico por el que se mueven, ya sea caminando en el caso de Smithson o volando globos con cámaras fotográficas en el de Basurama.

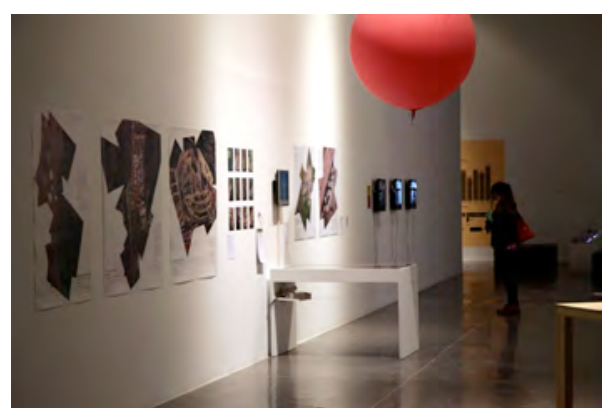

Ilustración 3. Basurama, vista de la exposición Defiende el territorio desde el aire, 2014.

\section{2.- EVOLUCIÓN DE LO SUBLIME: WALTER DE MARIA VS. SANTIAGO SIERRA}

En 1969 Walter De Maria realiza Las Vegas Piece. "Se trata de una franja, de un metro ochenta centímetros de anchura por casi cinco kilómetros de longitud, labrada en línea recta con un bulldozer en una extensa llanura del desierto de Nevada, que carece del más mínimo desnivel. La obra no sobresale del suelo, se manifiesta sólo como un cambio de textura en el terreno sobre el que los dientes

14 ÁBALOS, Iñaki. Atlas pintoresco. Vol. 2: los viajes. Barcelona: Gustavo Gili, 2008, p. 210. 
de la ancha pala de una máquina excavadora han levantado la rala vegetación para descarnar la superficie del suelo, dejando en él un simple surco rastrillado" ${ }^{15}$.

Esta creación exige unos determinados puntos de observación para hacer visible su "materialidad". El artista no pretende que el espectador consiga percibir la totalidad de la pieza jugando así con la sensación de infinitud e inmensidad. La obra ha sido pensada y realizada teniendo en cuenta que la escala, la horizontalidad y los posibles puntos de vista perspectivos van a proporcionar una imagen parcial, de modo que se produzca un conflicto entre conocimiento y percepción en la mente del espectador. Su ubicación en la zona central del desierto, refuerza el concepto de sublime y la paradoja de su dudosa materialidad. (llustración 4)

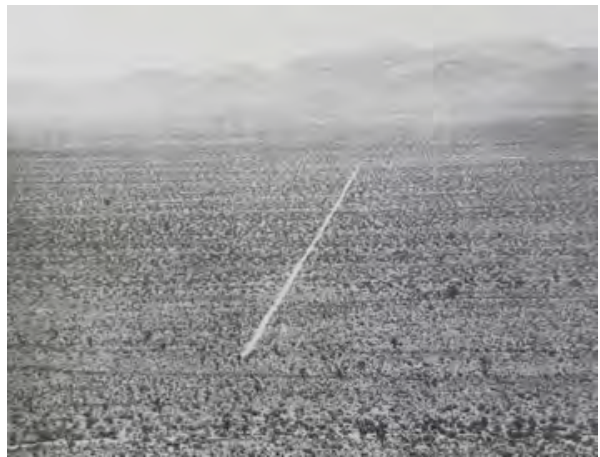

Ilustración 4.Walter De Maria, Las Vegas piece, 1969.

En octubre de 2012, el artista español Santiago Sierra, bajo la invitación de Artifariti y el Frente Polisario, realiza la intervención artística El graffiti más grande del mundo. Se trata de pieza ubicada en el desierto del Sahara Occidental/Argelia cerca de los campos de refugiados saharauis. Sierra ha intervenido en ocho kilómetros cuadrados del suelo del desierto para arar un mensaje de auxilio que puede leerse desde el cielo, a kilómetros de distancia. Un mensaje de alcance universal lanzado a la comunidad internacional que alerta sobre la precaria situación de los refugiados en el Sahara Occidental. Este graffiti en el territorio con las letras S.O.S (señal internacional de socorro) está escrito con la tipografía Arial Narrow con un tamaño de fuente de 6.800 .000 pt.

Este proyecto, que sólo puede verse de forma completa mediante imágenes tomadas por satélites y Google Earth, tiene una gran carga de de manda social. Hay un claro interés, por parte del artista, de convertir esta obra en una imagen a escala global rompiendo todo tipo de barreras físicas. (Ilustración 5)

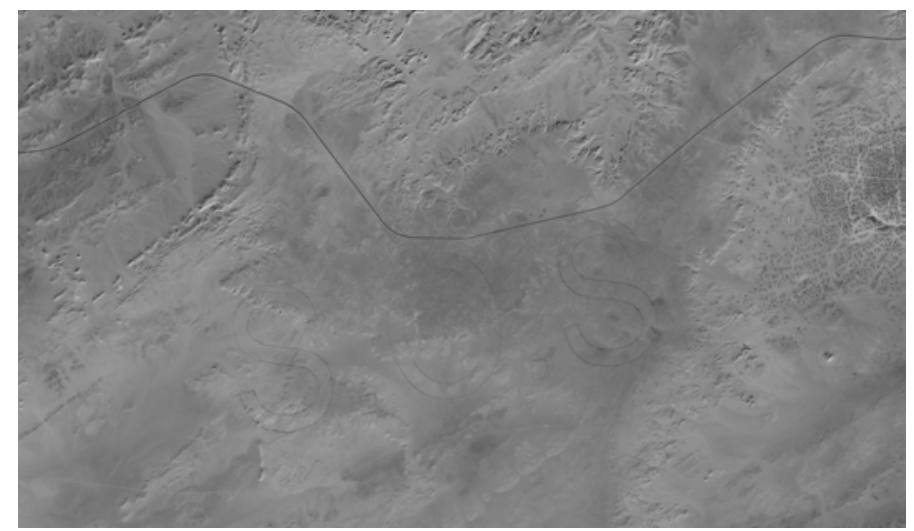

Ilustración 5. Santiago Sierra, El graffiti más grande del mundo, 2012.

Obviamente las dos piezas comparten una serie de puntos comunes: ambas están ubicadas en el desierto, ninguna de las dos puede verse en su totalidad desde el punto de vista de un espectador por lo que su visualización completa debe realizarse in visu y las dos obras tienen una escala territorial que cumple todas las condiciones de lo sublime (sensación de inmensidad e infinitud, imposibilidad de ver la obra en su totalidad). Pero, si bien, la obra de De Maria tiene una intención de juego perspectivo, de sensación de infinitud y de reforzar la idea de sublime en un paisaje como puede ser el desierto de Nevada; la pieza de Santiago Sierra potencia la idea de paisaje social. No tiene interés en mostrar la características físicas y geográficas de ese territorio, como si ocurre en Las Vegas piece de Walter De Maria, por el contrario Sierra incide en esa situación de precariedad e inestabilidad del pueblo saharaui. Una claro grito de

15 MADERUELO, Javier. “El artista de lo sublime. Walter De Maria, 1935-2013”. Arquitectura Viva, 2013, núm. 159, noviembre, p. 64. 
atención a la comunidad internacional para denunciar esta situación, para ello se aprovecha de la tecnología digital para que así el alcance sea mayor y más mediático, a la vez, que simbólico.

\section{4.- CONCLUSIONES}

En primer lugar podríamos establecer una diferencia entre los conceptos de paisaje y territorio y el tipo de mirada que implica cada uno: por un lado, tendríamos un punto de vista a la altura del ojo humano, del individuo, que relaciona el "paisaje" con lo "pintoresco", con una visión más parcial y acotada de la experiencia paisajista, con ver el paisaje desde puntos particulares; por el otro, hablaríamos de una vista aérea, cenital, de una mirada que observa desde la distancia, desde una posición de seguridad que nos permite observar y experimentar la inmensidad de la escala del "territorio" acercándonos al concepto de "sublime". Con esta segunda visión se percibe la idea de infinito, creándose “la ilusión perceptiva de una progresión sin fin"”.16.

En segundo lugar, en la actualidad, mientras que los mapas suelen ser resultados de una experiencia in situ o directa del territorio y nos aproximan al paisaje, más o menos natural, los dispositivos digitales crean un paisaje social que tiene que ver con la experiencia colectiva y cuestiones de control. Por lo tanto, lo importante no es ya el lugar sino el funcionamiento en red. El lugar pierde protagonismo frente al sistema, el conjunto, la red y la experiencia colectiva.

“[...] El arte es un mapa del mundo que salta de una escala a otra, pasando indiferentemente del 1/100.000 al 1/1: la distancia es la misma, pero el enfoque y el modo de captación cambian, a imagen de la fotografía satélite” ${ }^{17}$.

Podemos dejar de considerar, entonces, la "representación" como algo dependiente de la "apariencia". El mundo contemporáneo ya no se visualiza por su representación realista, sino por construcciones formales que mezclan diagramas, vídeos o modelizaciones. "Lo que ya no es figurable puede, por el contrario, seguir siendo medido, y servir de soporte a un trabajo de geómetra o de geógrafo" ${ }^{18}$. En este mundo tan desterritorializado y enteramente dominado por la técnica, la geografía ya no es solamente asunto de la ciencia, sino también de los artistas, que con sus nuevas miradas sobre los distintos territorios son capaces de reformular la idea de paisaje desde una perspectiva tan poética como crítica.

\section{FUENTES REFERENCIALES}

ÁBALOS, Iñaki. Atlas pintoresco. Vol. 1: el observatorio. Barcelona: Gustavo Gili, 2005. ISBN: 84-252-1991-4

ÁBALOS, Iñaki. Atlas pintoresco. Vol. 2: Ios viajes. Barcelona: Gustavo Gili, 2008. ISBN: 978-84-252-2118-7

ANSÓN, Antonio, et al. Paisaje y territorio. MADERUELO, Javier (dir.). Madrid: Abada Editores, 2008. ISBN: 978-84-96775-38-1

BOURRIAUD, Nicolas. "Topocrítica. El arte contemporáneo y la investigación geográfica”. En: HERNÁNDEZ-NAVARRO, Miguel Ángel (coord.). Heterocronías. Tiempo, arte y arqueologías del presente. Murcia: Cendeac, 2008. ISBN: 978-84-96898-24-0

CARERI, Francesco, Walkscapes. El andar como práctica estética. Barcelona: Gustavo Gili, 2005. ISBN: 84-252-1841-1

CHUECA, Fernando. Breve historia del urbanismo. Madrid: Alianza Editorial, 2000. ISBN: 978-84-206-5338-9

MADERUELO, Javier. “El artista de lo sublime. Walter De Maria, 1935-2013”. Arquitectura Viva, 2013, núm. 159, noviembre, p. $62-56$.

MADERUELO, Javier. El espacio raptado. Interferencias entre Arquitectura y Escultura. Madrid: Mondadori, 1990. ISBN: 84-397-1678-8

MEANA, Juan Carlos. "Paisajeando: orden de la experiencia vs. desorden del paisaje en la obra de Christian García Bello y Román Corbato". : Estudio, Artistas sobre outras Obras. 2015, vol 6, núm. 11, enero-junio, p. 233-248.

LONG, Richard. Richard Long Walking the line. Nueva York: Thames \& Hudson, 2002. ISBN: 978-05-0028-409-4

ROGER, Alain. Breve tratado del paisaje. MADERUELO, Javier (ed.). Madrid: Biblioteca Nueva, 2007. ISBN: 978-84-9742-681-7

16 MADERUELO, Javier. El espacio raptado. Interferencias entre Arquitectura y Escultura. Madrid: Mondadori, 1990, p. 186.

17 BOURRIAUD, Nicolas. Opus cit., p. 18.

18 Ibídem, p. 25. 